\title{
Age-Related Changes in Task-Switching Components: The Role of Task Uncertainty
}

\author{
Jutta Kray \\ Humboldt-University, Berlin, Germany \\ Karen Z. H. Li \\ Max Planck Institute for Human Development, Berlin, Germany
}

and

Ulman Lindenberger

Saarland University, Saarbrücken, Germany

\begin{abstract}
The present study examined age differences in executive functioning, using an externally cued task-switching paradigm. Two components of task switching were assessed: the ability to maintain and select among task sets (general switch costs) and the ability to switch between task sets (specific switch costs). In contrast to previous findings, we found large age-related differences in specific switch costs, especially when the number of potentially relevant task sets is increased from two to four. Age-related differences in general switch costs were absent when external task cues subserved executive processing in task switching. Generally, the findings suggest that age-related impairments in task-switching components vary as a function of task uncertainty, such as the presence of environmental prompts to behavior. ๑ 2002 Elsevier Science (USA)
\end{abstract}

Key Words: aging; executive control; attention; task switching; cognition; environmental prompts; task uncertainty.

In recent years, cognitive aging researchers have become increasingly interested in whether age-related differences in executive functioning may contribute to an understanding of age-related decline in various intellectual abilities such as fluid intelligence. Executive functions generally refer to higher level processes that organize lower level processes in order to regulate and verify behavioral activity. Among executive functions, the process of selecting among relevant goals or tasks seems critical for the control of human action, especially in the absence of environmental prompts to behavior. The problem of selecting among goals or task sets has been linked to performance deficits of frontal lobe patients, individual differences in fluid intelligence, and performance deficits in divided attention tasks (e.g., Duncan, 1995). Age-

The present research was supported by the Center for Lifespan Psychology, Max Planck Institute for Human Development. Special thanks go to Markus Metzler for programming the transition rates and to Annette Rentz-Lühning and Daniel Joram for their assistance with data collection.

Address correspondence and reprint requests to Jutta Kray, Department of Psychology, Saarland University, Im Stadtwald, 66123 Saarbrücken, Germany, or Karen Li, Centre for Research in Human Development, Department of Psychology, Concordia University, 7141 Sherbrooke St. West, Montreal, Quebec, H4B 1R6, Canada. E-mail: j.kray@mx.uni-saarland.de or kli@vax2.concordia.ca. 
related decline in a variety of cognitive tasks has also been attributed to deficits in the efficient control of one's own cognitive processing, that is, to executive functioning of the aging brain. Specifically, age-related performance deficits have been demonstrated (a) in divided attention or dual-task situations (e.g., Craik, 1977; Frensch, Lindenberger, \& Kray, 1999; Hahn \& Kramer, 1995; Hartley, 1992; Kramer, Larish, \& Strayer, 1995; Mayr \& Kliegl, 1993; Salthouse, Fristoe, Lineweaver, \& Coon, 1995; Verhaeghen, Kliegl, \& Mayr, 1997) and (b) in fluid intelligence tests, such as the Raven's Advanced Progressive Matrices Test (Raven, Court, \& Raven, 1987; Salthouse, 1991). Moreover, there is empirical evidence suggesting that age-related neurobiological changes in certain prefrontal brain structures are more pronounced than changes seen in most other cortical brain areas and that specific cognitive functions associated with the frontal lobes, such as inhibitory control or working memory processes, decline more rapidly than other cognitive functions in old age (see Fabiani \& Wee, 2001; Prull, Gabrieli, \& Bunge, 2000; Raz, 2000; West, 1996; van der Molen \& Ridderinkhof, 1998).

One frequently used paradigm, which may help to elucidate the processes underlying action control, is the task-switching paradigm. Specifically, task-switching research may allow separation of executive components and the study of their interactions (Allport, Styles, \& Hsieh, 1994; Jersild, 1927; Meiran, 1996; Rogers \& Monsell, 1995). Executive processing in task-switching situations refers to (a) the change of task-set configurations and (b) the selection of higher level goals or task sets and the maintenance of task representations (see Mayr, 2001). In most of the recent work, the first task-switching component has been defined as the difference between performance on responses in which a task switch occurs and those in which a task is repeated within blocks of trials (henceforth called specific switch costs; Meiran, 1996; Rogers \& Monsell, 1995). Specific switch costs are assumed to represent how well the cognitive system establishes new stimulus-response rules or task settings; that is, how well it activates currently relevant stimulus-response rules and deactivates previously relevant ones.

Several theoretical accounts have been proposed for explaining the phenomenon of switch costs. For instance, Allport et al. (1994; Allport \& Wylie, 1999) attributed switch costs as a type of proactive interference effect. According to their theoretical view, switch costs arise from a prolonged activation state of a previously relevant task set that decays only slowly and passively over time and thus interferes with performance of a newly relevant task set. In contrast, Rogers and Monsell (1995) suggested a distinction of endogenous and exogenous components of task control. In line with the Supervisory Attentional System (SAS) framework (Norman \& Shallice, 1986; Shallice, 1994), the endogenous component reflects a possible top-down activation of relevant and inhibition of irrelevant task sets by the SAS, which can be executed prior to target presentation. In addition, the exogenous component is triggered by the task-relevant stimuli themselves and is needed to complete the reconfiguration process. More recently, De Jong, Berendson, and Cools (1999) provided an alternative account - the failure-to-engage (FTE) account-of switch costs, which refers to failures to effectively use the opportunities for advance preparation. Efficient preparation "requires an explicit goal or intention to engage in such preparatory activities to be added to the basic goal structure that governs performance in the taskswitching paradigm, and retrieval and the carrying out of this intention at the proper time', (p. 391).

What about age-related changes in the ability to switch flexibly between cognitive sets? Some empirical studies have shown that age differences in specific switch costs are small or absent when general slowing of old adults' performance in response time tasks is taken into account (Brinley, 1965; Hartley, Kieley, \& Slabach, 1990; 
Kramer, Hahn, \& Gopher, 1999; Kray \& Lindenberger, 2000; Mayr, 2001; Mayr \& Kliegl, 2000; Salthouse, Fristoe, McGuthry, \& Hambrick, 1998; van Asselen \& Ridderinkhof, 2000). Similarly, Kramer et al. (1999) found significantly greater switch costs for older than for younger adults at the very beginning of practice but ageequivalent switching performance after three sessions of practice (see Experiment 1). However, Ridderinkhof, Span, and van der Molen (2002) reported a greater tendency for old adults than for young adults to perseverate in a WCST-like task. This pattern was attributed to specific age-related impairments in set-shifting abilities rather than to age-based deficits in rule-induction and monitoring performance.

Van Asselen and Ridderinkhof (2000) obtained significantly greater switch costs for old adults, compared to young adults, only for unpredictable task switches but not for predictable ones. ${ }^{1}$ This finding seems to be consistent with results indicating that the ability to prepare the cognitive system in advance is relatively preserved in old age (Kramer et al., 1999; Kray \& Lindenberger, 2000). One exception was reported by Kramer et al. (1999). In Experiment 3, they aimed at examining age differences in task-switching performance under conditions of increased memory load. In this experiment, participants had to switch after every fourth trial. In the paradigm, no explicit cue was provided which task to perform next; instead, task sequences were fully predictable. Hence, participants had to keep track of the task sequence while switching between cognitive tasks. With increasing memory load, old adults were not able to profit from increased RSI, but young adults did. In contrast, in the Kray and Lindenberger study, in which old adults showed reduced switch costs at long RSI's, participants were instructed to switch after every second trial.

Furthermore, age differences in specific switch costs are not modulated by the socalled backward inhibition effect obtained by Mayr and Keele (2000), that is, no specific age-related decline was found in inhibitory activity in terms of suppressing no longer relevant task sets (Mayr, 2001).

In sum, based on the recent findings, it seems that age differences in the ability to switch between task sets are modulated by conditions of novelty (unpredictable switches) and/or working memory constraints. In principle, the switching paradigm can be seen as a special case of a dual task paradigm in which participants are explicitly told what to do next. Hence, another possible source of set switching efficiency concerns the dual-task situation in general. This second task-switching component is assumed to reflect the requirement of keeping more than one task set active in working memory and determining which task set to perform next. The slow-down associated with such requirements has been termed "general switch costs" (Kray \& Lindenberger, 2000). We define general switch costs as differences in performance between switch blocks and single-task blocks. Thus, general switch costs are derived at a block level of analysis, whereas specific switch costs are computed at the trial level (for a similar distinction, see Mayr, 2001). Other researchers define general switch costs, which they call "mixing costs," as the difference between performance of trial repetitions in switch blocks and performance in single-task blocks (e.g., Los, 1999). Differences between these two approaches are discussed in more detail at the end of Results and Discussion.

A detailed discussion of several theoretical accounts of the phenomenon of mixing costs is provided by Los (1996). In his literature review, two general views on sources of mixing costs are distinguished-the strategic and the stimulus-driven views. A common assumption of the strategic view is that mixing costs arise because of differ-

${ }^{1}$ Problematic with the interpretation of this finding is that participants received much more practice in the predictable than in unpredictable switches. Thus, age differences in specific switch costs may disappear also for unpredictable task shifts with increasing practice. 
ences in the preparedness for upcoming events due to greater uncertainty about the next trial in mixed-compared to single-task blocks. Examples of preparation models are (a) criterion-based models, which assume that response criteria such as speedaccuracy trade-offs are differently set in single- and mixed-block conditions; (b) arousal models, which argue that thresholds at which stimuli become arousing are set differently in single versus mixed blocks; and (c) structural models, such as twostage models, which propose that two stages are involved in mixed blocks, namely a preselection between task sets followed by the selection of S-R mapping within task sets (see also Rogers \& Monsell, 1995). Finally, Strayer and Kramer (1994a, 1994b) point to the fact that single and mixed blocks differ in effective memory load. Hence, it is possible that response criteria are adjusted at the level of effective memory load.

Stimulus-driven accounts of mixing costs suppose that more trial-to-trial adaption is necessary due to greater variability in mixed- than in single-task blocks. For instance, sequential effects are usually seen as stimulus-driven processes reflecting residual activity of preceding trials. Two mechanisms that might explain sequential effects are associative priming and mental inertia (cf. Los, 1996; see also Allport et al., 1994).

Similar to two-stage models, we also assume that two processes are involved in task switching. One selection process operates at the level of task sets. In the present context, precues of task sets may facilitate the selection processing for setting up the cognitive system for the relevant task because task cues reduce uncertainty about what to do next. For this reason, general switch costs are expected to be lower in precuing paradigms than in paradigms without task-set precues. Then, a second selection process follows that determines the correct response on the basis of target properties.

Recent empirical studies on age differences in general switch or mixing costs found significantly greater general switch costs for old than for young adults even when general slowing was taken into account (Kray \& Lindenberger, 2000; Mayr, 2001; van Asselen \& Ridderinkhof, 2000). Moreover, Kray and Lindenberger (2000) and Mayr (2001) found larger age differences in general than in specific switch costs. In these studies, older adults had greater difficulty than younger adults in selecting among potentially relevant task sets while switching. This pattern appears to be robust across a variety of experimental contexts such as extensive practice, increased preparation time, and different task domains. Importantly, general and specific switching components are separable into two distinct but intercorrelated latent factors (Kray \& Lindenberger, 2000). However, the findings may be restricted to a particular environmental context in which control demands were high, that is, when external cues were absent. A more recent study (Mayr, 2001) replicated the finding of larger age differences in general switch costs (global set-selection costs) than in specific switch costs (local switch costs) under conditions of stimulus ambiguity and full response-set overlap. Mayr (2001) interpreted this as an age-related impairment in the ability to differentiate among task sets, which is magnified when ambiguity is induced at stimulus and response levels. Again, age-related impairments in task-switching performance were found under conditions of "task uncertainty", that is, of low environmental prompts to behavior (e.g., Duncan, 1995).

Further evidence for the importance of the general switching component in efficient action regulation comes from recent neurocognitive studies. For example, Keele and Rafal (2000) investigated general and specific switching components with a cued switching paradigm that compared patients with frontal lobe damage and matched controls. However, specific switch costs did not differ across groups but patients with lesions in the left frontal lobe showed larger general switch costs than the other 
groups. Mecklinger, von Cramon, Springer, and von Cramon (1999) also found that specific switch costs were not significantly larger in patients with brain damage in the left or right cortex. Moreover, specific switch costs were not increased in patients with frontal lobe damage relative to patients without frontal lobe damage.

Taken together, the findings from cognitive aging and neuroscience research suggest that the selection processes (associated with general switch costs) which prepare the system for an upcoming action appear to be related to frontal lobe functioning and are also affected by aging. In contrast, switching processes (associated with specific switch costs) may not be critically associated with prefrontal brain structures. Instead, recent fMRI studies support the view that the anterior cingulate seemed to be critical for conflict detection and resolution at the level of response sets rather that at the level of task sets (e.g., Carter et al., 1999).

A major goal of the present study was to examine whether the same pattern of age differences in general and specific switch costs can be found under conditions of greater environmental support but lower predictability of switching. From the literature on cognitive aging (see McDowd \& Shaw, 2000; Zacks, Hasher, \& Li, 2000, for reviews), we expected that task cues would help older adults organize cognitive processing during task switching (see also Duncan, 1995; Hartley et al., 1990) and should thus reduce the age differences in general switch costs. The inclusion of task cues may change the activation of the currently triggered task sets relative to the other potentially relevant task sets. That is, selecting among task sets or goals should be facilitated by external cues. In contrast, with no environmental cues, the activation of the currently relevant task set must be internally triggered and the other potentially relevant task sets must be selected against (see Li, Lindenberger, Rünger, \& Frensch, 2000, for similar ideas).

A related issue is whether age differences in task-switching components would be affected by the number of alternative task sets. We expected that the selection among many tasks should take more time, that is, general switch costs should be greater, when the number of potentially relevant task sets is increased. Furthermore, we assumed that specific switch costs should be magnified with increasing numbers of task sets because the selection demands should be large when there is a complete overlap of response mappings across task sets. For example, Meiran (2000) found that specific switch costs are reduced when ambiguity at the response-set level is reduced, that is, when two task sets were mapped onto different response keys instead of the same response keys.

To unconfound possible effects of task set number and switch density on general and specific switch costs, we orthogonally manipulated (a) the number of sets to be held in working memory and (b) the frequency or density of task switches to be performed within a given block of trials.

In sum, the goals of the present study were, first, to determine if greater age effects on general compared to specific task-switching components observed in task conditions without provision of external cues would also be observed when external task cues are present. Second, we wished to examine whether age differences in general and specific switch costs are affected by the number of currently relevant tasks, switch density, or both.

\section{METHOD}

\section{Participants}

Seventy-three participants were recruited for a single-session study. The sample was stratified by age and gender (see Table 1). One young adult was excluded from data analysis due to extremely high error 


\section{TABLE 1}

Descriptive Statistics for Younger and Older Adults for Self-Rated

Health, Vocabulary, and the Digit-Symbol Substitution Test

\begin{tabular}{llllll}
\hline & \multicolumn{2}{c}{ Young } & & \multicolumn{2}{c}{ Old } \\
\cline { 2 - 3 } \cline { 5 - 6 } Variable & $M$ & $S D$ & & $M$ & $S D$ \\
\hline$n$ & 36 & & 36 & \\
$\%$ female & 50 & & 50 & \\
Age $^{a}$ & 23.06 & 2.99 & 66.83 & 2.94 \\
Self-reported $^{\text {Health }}{ }^{b}$ & & & & \\
$\quad$ Physical & 1.86 & 0.72 & & 2.31 & 0.52 \\
$\quad$ Mental & 1.81 & 0.58 & 2.03 & 0.51 \\
$\quad$ Vocabulary & 25.00 & 4.45 & 27.44 & 3.38 \\
Digit-Symbol & 62.08 & 8.57 & 44.83 & 8.39 \\
\hline
\end{tabular}

${ }^{a}$ Age range of young adults (19-30 years) and of old adults (59-72 years).

${ }^{b}$ Self-reported health was assessed with a Likert scale ranging from

1 (excellent) to 5 (very poor).

rates relative to group means. Almost all of the young participants were recruited from the Humboldt University at Berlin or from a subject pool of the Max Planck Institute for Human Development. Most of the older adults were recruited from a subject pool of the Max Planck Institute for Human Development or by personal contact. All subjects received 40 DM (about U.S. \$20.00) for participation. Demographic characteristics for each age group are summarized in Table 1.

Younger and older adults reported themselves to be in good mental and physical health. No significant age differences were obtained in subjective mental health scores, but older adults rated themselves as significantly less healthy than young adults, $t(70)=2.98, p<.01$. In line with a number of previous findings (Verhaeghen \& Salthouse, 1997), differential age trends were found for two intellectual abilities: perceptual speed and knowledge. Highly negative age differences were observed for perceptual speed, as measured by the Digit-Symbol Substitution Test (Wechsler, 1982), $t(70)=-8.63, p<.01$. In contrast, positive age differences were obtained for knowledge, that is, older adults had significantly higher scores in a vocabulary subtest ${ }^{2}$ than did younger adults, $t(70)=2.63, p=.01$.

\section{Materials}

We used IBM-compatible computers for data collection. Stimuli were presented on a CTX 17-inch color monitor with a dark blue background. Responses were registered by left and right "control" keys. All stimuli were familiar German words. Participants were instructed on the four different tasks, in which they decided (a) if the stimulus was an animal or nonanimal, (b) if the number of syllables was equal to one or two, (c) if the number of letters was odd or even, or (d) if the word contained the letter $\mathrm{H}$. For all four tasks, the same two response keys were used. Table 2 outlines the left-right response mappings and external cues for each task.

TABLE 2

Tasks, Response Assignment, and External Cues

\begin{tabular}{|c|c|c|c|c|}
\hline \multirow[b]{2}{*}{ Tasks } & \multicolumn{2}{|c|}{ Response assignment } & \multicolumn{2}{|c|}{ External cues } \\
\hline & Left key & Right key & Cue & Color \\
\hline A: Category? & Nonanimal & Animal & $\mathrm{K}$ & Green \\
\hline B: Number of syllables? & One & Two & $\mathrm{S}$ & Blue \\
\hline C: Number of letters? & Unequal & Equal & $\mathrm{Z}$ & Yellow \\
\hline D: Letter $\mathrm{H}$ ? & No $H$ & With $\mathrm{H}$ & B & Red \\
\hline
\end{tabular}

${ }^{2}$ In the present study, we used a computerized version of the vocabulary subtest Spot-a-Word that was adapted from the Lindenberger, Mayr, and Kliegl (1993) study and included 35 items instead of 20 items. 
These four two-choice tasks $(2 \times 2 \times 2 \times 2)$ resulted in 16 possible stimulus-attribute combinations. For instance, the target CAT is characterized as a word belonging to the category of animals, the number of syllables is equal to one, the number of word letters is uneven, and the word does not contain letter H. For each stimulus-attribute combination, we found eight stimuli except for one combination (animals, two syllables, even, with $\mathrm{H}$ ) for which we found only six different stimuli.

To provide external cues, a single letter indicated which task to perform in the next trial: $\mathrm{K}$ for the category task; $\mathrm{S}$ for the syllable task; $\mathrm{Z}$ for the number of letters task; and $\mathrm{B}$ for the letter $\mathrm{H}$ task. Cues and targets were displayed in uppercase 34-point bitmap font (Swiss regular). To help participants remember the cue-task relations, the cues and targets were shown in a different color for each task set. In addition, we placed a small sign above the keyboard listing the stimulus-response relationships.

\section{Procedure}

The study lasted approximately $2 \mathrm{~h}$ with a 10 -min break after about $50 \mathrm{~min}$. Participants first completed a consent form and a short demographic questionnaire. Next, we administered the Digit-Symbol Substitution Test in groups of two to four participants. Then, participants moved to individual testing rooms and performed the vocabulary test and then the experimental tasks on computer. All participants had a short break after the first hour of testing.

In the experimental task, participants began with a practice block of 48 trials in which they performed all of the four tasks in combination. Then, they worked through 36 experimental blocks: 12 blocks for each of the set size conditions (1, 2, and 4). In Set Size 1, participants performed Task A, or B, or C, or $\mathrm{D}$ within a given block. In Set Size 2, they switched between Task A and B in half of the blocks and between Task C and D in the other half. Finally, in Set Size 4, participants performed all four tasks in each block. For switch blocks (Set Sizes 2 and 4), we manipulated the switching rate by constructing task sequences that differed in the percentage of switch to nonswitch trials $(37.5,50$, and $75 \%)$. The task sequences were randomized with two constraints: (a) all four tasks were shown an equal number of times and (b) there was a near-equal number of task transition pairs (e.g., AA, AB, AC, and AD).

Each block consisted of 33 trials, yielding a total of $36 \times 33=1188$ trials. The first trial in each block was not analyzed and those trials were always drawn from the pool of practice stimuli. Each test block consisted of two word lists that were randomly assigned to the experimental conditions. Furthermore, to control for sequential effects, participants were randomly assigned to one of six possible orderings of the set-size factor (cf. Kray \& Lindenberger, 2000, where order was fixed).

Trial procedure. We used a task-switching paradigm in which a fixed cue-target interval of 1000 ms was given before the appearance of the target. Together, the cue and target then remained for a maximum $5000 \mathrm{~ms}$ or until a response was made. The time between response (or timeout) and the appearance of the next cue (response stimulus interval) was fixed at $1000 \mathrm{~ms}$.

Instructions were given both verbally and visually on the computer. Participants were told to respond as quickly and accurately as possible. On test trials, feedback was only given after incorrect responses. Depending on the error type, the feedback "wrong" or "too slowly" was presented below the target for $1000 \mathrm{~ms}$. The procedure in the practice block was similar to the experimental blocks, but participants had no time limits for responding, and feedback ("correct" or "wrong") was given after every trial.

\section{RESULTS AND DISCUSSION}

The focus of data analysis was on mean latencies for correct responses. Overall, the error rates were low: We obtained very few incorrect responses $(2.8 \%$ for young adults and $2.4 \%$ for old adults) and responses exceeding $5000 \mathrm{~ms}(0.1 \%$ for young adults and $0.7 \%$ for old adults). For all analyses of variance, we used logarithmtransformed reaction times so that mean differences were equivalent to ratio scores and therefore less sensitive to differences in baseline performance (Kliegl, Mayr, \& Krampe, 1994; Ratcliff, 1993). We show log-transformed latencies in all figures and, for reference, untransformed mean latencies in Appendices 1 and 2.

\section{Set Size Effects}

To examine whether age differences in general and specific switch costs are affected by the number of potentially relevant task sets, we carried out a repeatedmeasures ANOVA with Age Group (young, old) as a between-participants variable 
and three a priori within-participants contrasts: General switch costs were indicated by Set Contrast 1, which tested means of Set Size 1 against means of Set Sizes 2 and 4. In Set Contrast 2, means of Set Size 2 were tested against means of Set Size 4 to investigate further effects of Set Size. Specific switch costs were indicated by the Switch Contrast, in which means of switch trials were tested against means of nonswitch trials. We also ran within-subjects contrasts without Age Group as a between-participants variable to determine whether general and specific switch costs are affected by the set size variable. Figure 1 shows the log-transformed latencies as a function of Age Group, Set Size, and Trial Type.

In general, we found significant general switch costs overall (Set Contrast 1), $F(1$, $70)=108.99, M S E=0.48, p<.01$, suggesting slower latencies for switch blocks versus single-task blocks. We also observed substantial specific switch costs (Switch Contrast): $F(1,70)=306.15, M S E=0.04, p<.01$. However, we observed no significant differences when participants switched between 2 versus 4 task sets: that is, Set Contrast 2 was nonsignificant, $F(1,70)=0.58, M S E=0.18, p>.01$. Thus, general switch costs were not enlarged when the number of task sets was increased. In contrast, we obtained significantly larger specific switch costs when the number of task sets was increased from two to four (Switch Contrast $\times$ Set Contrast 2), $F(1$, $70)=14.17, M S E=0.02, p<.01$.

We also obtained substantial age differences in general switch costs (Age Group $\times$ Set Contrast 1$), F(1,70)=5.64, M S E=0.48, p=.02$, suggesting that older adults showed slower latencies in switching conditions than in single-task conditions compared to younger adults. Moreover, we found significant age differences in specific switch costs (Age Group $\times$ Switch Contrast), $F(1,70)=25.97, M S E=0.04, p<$ .01 . That is, within switch blocks, older adults were significantly slower than younger adults in switch trials relative to nonswitch trials. Additional post hoc analyses indicated that the age differences in general switch costs (Set Contrast 1) were only significant for switch trials and not for nonswitch trials, $F(1,70)=10.16, M S E=$ $0.17, p<.01$. Hence, age differences were confined to switch trials which stands in clear contrast to most of the previous findings on age differences in task switching (e.g., Kray \& Lindenberger, 2000; Mayr \& Kliegl, 2000; van Asselen \& Ridderinkhof, 2000).

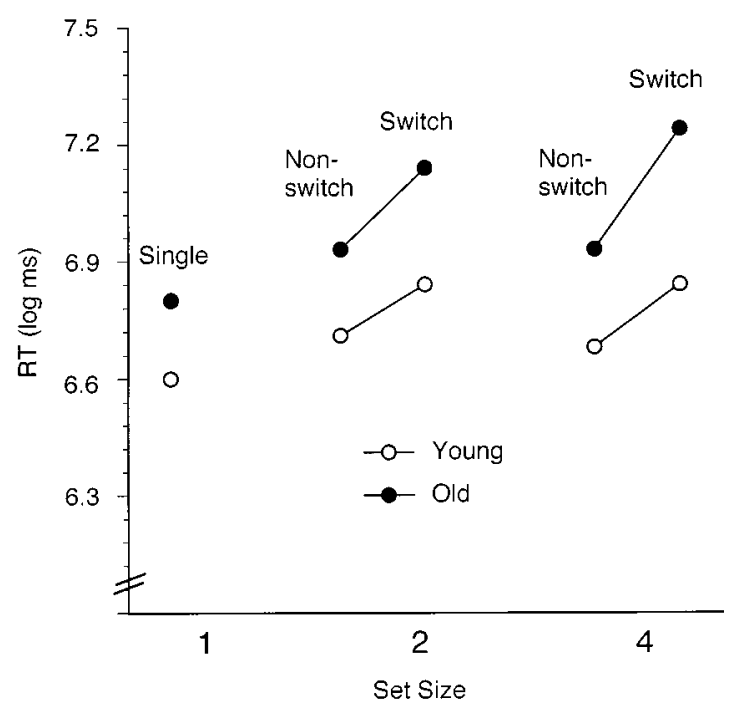

FIG. 1. Means of log-transformed RTs as a function of age group, set size, and trial type. 


\section{Switch Rate Effects}

To examine the influence of the density of a task switch for age differences in general and specific switch costs, we computed a repeated-measures ANOVA with Age Group (young vs old) as a between-participants factor and Trial Type (switch vs nonswitch), Switch Rate $(37.5,50$, and $75 \%$ ), and Set Size (2 vs 4) as withinparticipants factors. The results are straightforward (see Fig. 2). The density or rate of switching interacted with no other experimental variables in the present study. Thus, the observed age differences in general and specific switch costs were not influenced by the rate of switching (all $p$ 's $\geq .20$ ).

\section{Task-Specific Effects}

We also explored whether age differences in general and specific switch costs varied as a function of the task-specific processing required for performing each of the four tasks. Although we used only verbal materials in the experiment, the cognitive operations for each task were quite different. For example, semantic retrieval was important for the category task, but was less important for counting the number of letters or syllables contained in a word. To examine task-specific effects on the pattern of age differences in general and specific switch costs, we first conducted a repeatedmeasures ANOVA using Age Group (young vs old) as a between-participants factor and Set Size (1 vs 2 vs 4) and Task (category vs syllable vs number of letters vs letter $\mathrm{H}$ ) as within-participant factors. This overall analysis yielded a significant triple interaction of Age Group, Set Size, and Task, $F(6,70)=5.77, M S E=0.005, p<$ .01. Therefore we computed separate ANOVAs for each of the four tasks.

Results were relatively consistent across all four tasks. General switch costs (Set Contrast 1) were found for all four tasks (all $p$ 's $<.01$ ). In contrast, changing the set size from two to four (Set Contrast 2) did not increase response latencies for any of the tasks ( $p$ 's $>0.10$ ). Moreover, specific switch costs were highly significant for all four tasks (all $p$ 's $<.01$ ).

Significant age differences in general switch costs (Age Group $\times$ Set Contrast 1 ) were only observed for the category task, $F(1,70)=4.96, M S E=0.61, p=.03$, and the syllable task, $F(1,70)=20.41, M S E=0.71, p<.01$, favoring younger

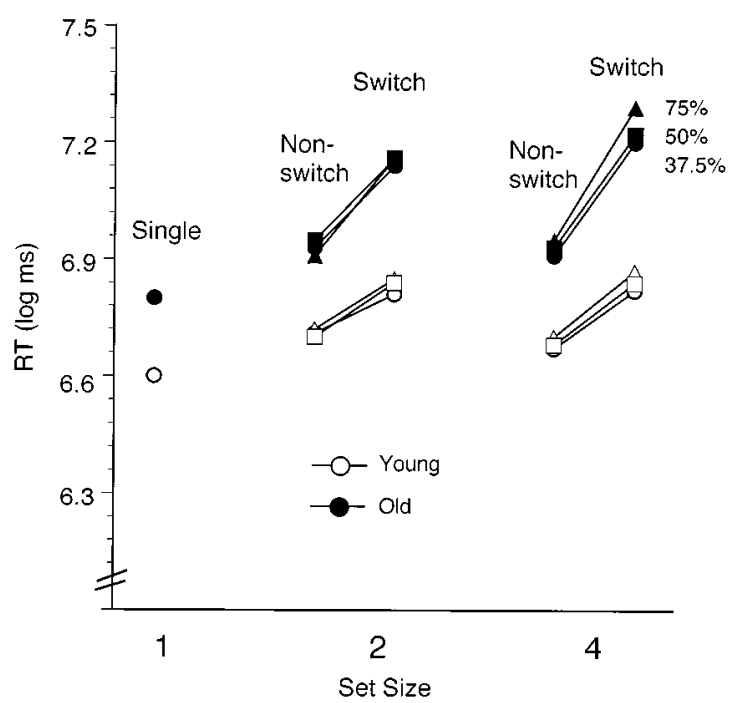

FIG. 2. Means of $\log$-transformed RTs as a function of age group, set size, and switch rate. 
adults. However, post hoc analyses using the category task data indicated that age differences in general switch costs (Age Group $\times$ Set Contrast 1) were only significant for switch trials, $F(1,70)=11.63, M S E=0.21, p<.01$, and not for nonswitch trials. In contrast, for the syllable task, Age Group $\times$ Set Contrast 1 was significant for both nonswitch, $F(1,70)=8.93, M S E=0.15, p<.01$, and switch trials, $F(1$, 70) $=29.22, M S E=0.24, p<.01$.

In addition, we obtained significant age differences in specific switch costs for all four tasks, suggesting that older adults were more slowed for switch than for nonswitch trials in the category task, $F(1,70)=14.66, M S E=0.01, p=.01$; the syllable task, $F(1,70)=20.41, M S E=0.71, p<.01$; the letter $\mathrm{H}$ task, $F(1,70)=12.48$, $M S E=0.06, p<.01$; and for the number of letters task, $F(1,70)=4.43, M S E=$ $0.06, p=.04$.

In sum, we obtained substantial age differences in specific switch costs, whereas age differences in general switch costs were only moderate or absent; that is, they were confined to switch trials. This pattern of results generalized across four task sets even though they differed in difficulty and involved different task-specific processing (cf. Kramer et al., 1999; Kray \& Lindenberger, 2000; Mayr \& Kliegl, 2000).

\section{A Comparison of Internally and Externally Cued Switching Paradigms}

The present pattern of results is in direct opposition to that of our first study (Kray \& Lindenberger, 2000). In this study, we found larger age differences in general than in specific switch costs. In order to explore whether age differences in general and specific switch costs differ as a function of the presence versus absence of task cues, we compared switching data across both studies.

The following analysis was restricted to those experimental conditions that were closely comparable across experiments. In both studies, a switching paradigm was used in which participants performed two task sets in isolation (Set Size 1) and switched between both task sets (Set Size 2). Switching rate in mixing blocks was $50 \%$. In contrast to the present study (Study II), in the Kray and Lindenberger study (Study I) no task cues were used. Instead, task sequences were fully predictable and consisted of AABB runs. Familiar words were used as stimulus materials in both studies. In both studies, the two tasks were to classify words in terms of semantic categories or in terms of number of syllables. In the first task, participants were asked to decide whether the word referred to an animate or inanimate object (Study I) or whether the word belonged to the category of animals (Study II). In both studies, participants were instructed in the second task to decide whether the number of syllables was equal to one or two. In both studies only two response keys, a left and right response button, and two effectors (left and right index finger ) were used.

In Study I, time intervals between response and presenting the next target were set to 200 and $1200 \mathrm{~ms}$. In Study II, time intervals between cue and target presentation were fixed to $1000 \mathrm{~ms}$. The following analysis only includes those blocks with time intervals of $1200 \mathrm{~ms}$.

A further difference between both studies refers to the amount of practice. The first study consisted of an introduction phase, pre- and posttest, and four sessions of practice. The second study was a single-session experiment. Therefore, we only include data from the pretest session of Study I for the following analysis.

In the first study, we investigated 39 younger adults (20-40 years of age; mean age $=29.5)$ and 39 older adults (61-80 years of age; mean age $=69.5)$, which is comparable to the sample characteristics of the present study (see Table 1).

We conducted an ANOVA with Age Group (young vs old) and Cue (present vs absent) as between-participants factors and Trial Type (single vs nonswitch vs switch) 
as a within-participant factor. Furthermore, two orthogonal contrasts were specified for Trial Type: First, mean latencies of both single tasks were tested against mean latencies of pooled nonswitch and switch trials (general switch costs). Second, mean latencies of nonswitch trials were tested against mean latencies of switch trials (specific switch costs). Results indicated substantial general switch costs, $F(1,147)=$ 218.20, $M S E=0.15, p<.01$, and specific switch costs, $F(1,147)=143.39, M S E=$ $0.03, p<.01$, across both studies. When external task cues were absent, general switch costs were significantly larger, $F(1,147)=5.12, M S E=0.15, p=.02$, as were specific switch costs, $F(1,147)=9.69, M S E=0.04, p<.01$, than when cues were provided (see Fig. 3).

Separate analyses of variance for younger and older adults showed that for older adults, general switch costs were significantly reduced with the provision of external cues, $F(1,73)=3.94, M S E=0.19, p<.01$, in line with the environmental support view. Further, for young adults, specific switch costs were significantly smaller under externally cued conditions, $F(1,73)=11.59, M S E=0.03, p<.01$.

Because the present findings were in the opposite direction to our previous findings, we aimed to compare age differences in general and specific switch costs across both studies, that is, as a function of the presence and absence of task cues. The additional analysis suggests that general switch costs were greater for uncued versus cued task switching (cf. De Jong et al., 1999; Hartley et al., 1990). In contrast to previous findings, we found substantial age differences in specific switch costs for externally cued conditions. These findings cannot be a result of age differences across both studies because for single-task conditions, younger and older adults performed better under internally cued conditions in the previous study (means of log-transformed RTs for the young $=6.41$ and for the old $=6.59$ ) than under externally cued conditions in the present study (means of log-transformed RTs for the young $=6.53$ and for the old $=6.63$ ). However, we recognize that the nature of the preceding comparisonsbetween subjects and across experiments-limits the inferential power of our analysis.
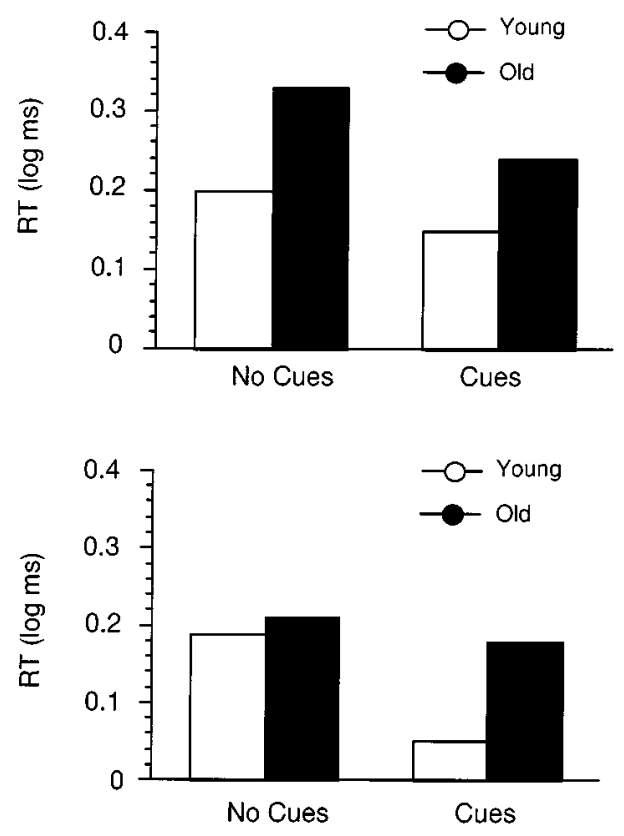

FIG. 3. A comparison of general switch costs (top panel) and specific switch costs (bottom panel) between cued and noncued switching paradigms. 
The most interesting result of the present study is that the presence of task cues seems to change the relative magnitude of age differences in two components of task switching. However, this finding is based on a comparison of two highly similar experiments that nonetheless differ in some details. In the following, we consider some factors that might modulate these inconsistencies.

Other possibly relevant differences between the task demands of the present experiment and the demands in the tasks reported in Kray and Lindenberger (2000) concern the predictability of the switch and the amount of preexperimental practice. In Kray and Lindenberger (2000), switches were internally cued but fully predictable (i.e., the task sequence was $\mathrm{AABBAABB}$....). In the current experiment, task cues were randomly selected. The absence of task cues and full predictability may result in a highly activated state of all possible task sets throughout the entire sequence of switches (cf. Li et al., 2000), thereby creating an overall slowdown of performance relative to single-task conditions (i.e., general switch costs). In contrast, in the present experiment advance preparation of the entire switch sequence was impossible but probably all possible sets were in a less activated state and only the currently relevant task was highly activated by the task cue. As a consequence, age differences in switch costs were observed at the specific rather than the general level (see Fig. 3).

A further factor that might influence the cross-experiment findings is the difference in preexperimental practice. In the earlier study (Kray \& Lindenberger, 2000), participants performed four practice blocks for each of the experimental conditions in a separate session. In the present study, participants received only one practice block for all experimental conditions. It is thus conceivable that the presently reported age differences in specific switch costs would disappear with additional practice. For instance, Kramer et al. (1999) found that early in training, older adults showed significantly slower performance than younger adults in switch versus nonswitch trials, but by the end of training, switching performance became equivalent between the age groups.

Despite problems in interpretating across-experiment data, it is interesting to speculate what theoretical accounts might explain the modulation of age differences in general and specific task switching as a function of precueing. One possible function of external task cues is to facilitate the retrieval of currently relevant task-set representations. Task cues help to reduce task uncertainty in competition situations such as dual-task like situations (cf. Los, 1996). With the absence of task cues, problems in differentiating among task sets may be due to similar activation states for all relevant task sets. If the currently relevant task set (or goal) is not facilitated by task cues, this might also result in an insufficient transfer of the task-set representation into the corresponding stimulus-response rules (schemas) that is needed to reconfigure task sets (cf. failure-to-engage account; De Jong et al., 1999).

In our view it seems fruitful to pursue the latter account by determining the boundary conditions that modulate the activation of relevant goals as well as their relation to the retrieval of stimulus-to-response mappings. Specifically, external task cueing and verbal processing may strongly influence the activation of goals as a precondition for implementing the relevant stimulus-response rules. In addition, efficient reconfiguration may also depend on properties of the stimuli themselves and the amount of response overlap.

To examine age differences in task switching we aim to compare age effects in two components - the switching process itself and the processes related to the dualtask situation itself. In both of our studies, general and specific switch costs were expressed in the factor Trial Type as two orthogonal contrasts. In the first contrast, we tested mean RT of single tasks versus mean RT of nonswitch and switch trials 
(general costs). In the second contrast, we tested the mean RT of nonswitch versus the mean RT of switch trials (specific costs). The specification of general and specific costs in two orthogonal contrasts permits the identification of group differences in general and specific costs that are statistically independent of each other within the same analysis of variance (i.e., only 1 degree of freedom is needed). As a drawback, additional post hoc comparisons between single and nonswitch trials are needed if substantial age differences in specific switch costs are found in order to examine their influence on age differences in general costs.

An alternative way of analyzing the data is to compute repeated contrasts. In this manner, age effects in general switch costs are not directly influenced by age effects in specific switch costs. However, the drawback of this method is that the two types of costs are not statistically independent of each other. In the Kray and Lindenberger study, the overall analysis of age differences in general and specific switch costs indicated that age differences in specific switch costs were small to nonsignificant. Nevertheless, we reanalyzed the most important findings as suggested by two of the reviewers and found no difference between the two ways of analyzing the data (see Appendix 3).

\section{GENERAL DISCUSSION}

The major goals of the present study were (a) to extend previous evidence pointing at greater age-related deficits in the ability to select among potential task sets than in the ability to reconfigure task sets to an externally cued task switching context and (b) to examine whether age differences in task switching are influenced by the number of potentially relevant task sets and switch density.

With the inclusion of external task cues in the present study, we found substantially greater general switch costs when comparing single task performance with two-task performance. General costs were not further augmented when the number of potentially relevant task sets increased from two to four. However, we obtained no age differences in general switch costs for most of the experimental task conditions. This is in clear contrast to other findings in the literature (Kray \& Lindenberger, 2000; Mayr, 2001; van Asselen \& Ridderinkhof, 2000). Apparently, both young and old adults were able to use external prompts to set up the currently relevant task settings for efficient switching (see Hartley et al., 1990; Kramer et al., 1999).

\section{Comparison with Other Findings}

Contrary to the present results, Mayr (2001) recently reported significant age differences in general switch costs under conditions of high stimulus ambiguity and full response-set overlap, even though explicit task cues were provided. According to his interpretation of findings, the observed age differences in general switch costs may reflect an age deficit in updating internal control settings in situations of uncertainty. Following this logic, one might also expect that increasing the set size from two to four should increase the stimulus ambiguity and response-set overlap. As reported, however, general switch costs and age effects therein were not magnified by this set size increase in the present study.

However, there are ways to reconcile these conflicting findings. Two obvious differences between the two studies concern the stimulus materials and the number of stimuli. For instance, Mayr (2001) used geometric stimuli that differ in shape, size, and color. In contrast, we used common words, and the tasks required the extraction 
of visual or semantic information. However, it is unlikely that the difference between the two outcomes is due to this difference in materials because findings suggesting that task-switching components reflect domain-general constraints of the cognitive system are very robust against large amounts of practice and are highly intercorrelated across task domains (numerical, figural, and verbal; see Kray \& Lindenberger, 2000).

A second possibility is that variations in the number of stimuli used across experiments result in different patterns of switch costs for younger and for older adults. For example, Mayr (2001) used 8 different stimuli in one experiment in comparison to the 62 stimuli used in the present study. If the number of stimulus repetitions is large, then uncertainty (or interference) to select among currently relevant task sets will be increased and the response criterion is set more conservatively for switching conditions (Los, 1999), so that latencies would increase. The current literature does not indicate whether this would have an impact on task switching performance. In other attentional paradigms such as Stroop interference or negative priming, targetdistractor ratio seems to matter (e.g., MacLeod, 1991; Tipper, Weaver, Cameron, Brehaut, \& Bastedo, 1991).

Another component proposed to explain age-based differences in general switch costs are age-related differences in working memory load (Kramer et al., 1999). Cuing of task set should lead to dramatic decrements in this load and reduce age differences. In line with this account, older and younger adults in the present study did not differ in selecting and maintaining mental sets, independently of the number of potentially relevant task sets. Thus, it seems that both young and old adults fully rely on external memory aids under conditions of precueing. It is still an open question whether the number of relevant task sets increases the magnitude of age difference in general switch costs when external cues are absent.

Inconsistent with our own previous results, we obtained significantly greater specific switch costs for older than for younger adults. Moreover, age differences in those costs were even more pronounced when the number of task sets was increased. The findings seems to suggest that older adults' ability to reconfigure stimulus to response mappings is impaired when interference at the response level is increased, that is, when stimulus attributes of all four tasks call for the same responses.

\section{Generality or Specifity of Age Changes in Task Switching?}

Generally, some cognitive aging researchers favor the concept of a simple, general mechanism that can explain age-related decline in several cognitive tasks. For instance, Salthouse (1996) collected multiple empirical evidence that age-based changes in speed of information processing are a good or perhaps the best predictor of age-related changes in abilities from the fluid intelligence domain. Other researchers argue that there is also evidence in favor of function-specific processing in old age (e.g., Mayr \& Kliegl, 1993). For example, recent converging evidence supports the view of separate subsystems within the frontal cortex that show differential susceptibility to normal aging. For instance, Phillips and Della Sala (1998) suggested that the pattern of age change is best described in terms of age-related deterioration in the dorsolateral prefrontal cortex that is recruited for solving fluid intelligence tests. In contrast, the orbitoventral prefrontal cortex appears to be involved in decision making and emotionally problem solving and is less sensitive to normal aging.

What about age changes in task switching components? Recent aging studies used modified versions of the task switching paradigm that allows for the comparision of age differences in cognitive or executive processes, such as the selection and maintenance of task sets and the selection or reconfiguration of stimulus-response sets under 
different experimental conditions. Recent behavioral data on age differences in task switching suggested that age-related impairments in the two task-switching components vary as a function of task uncertainty, such as the presence of task cues (Kray \& Lindenberger, 2000), stimulus ambiguity and response-set overlap (Mayr, 2001), or unpredictability of task switches (van Asselen \& Ridderinkhof, 2000).

How can cognitive neuroscience be helpful in evaluating current theories of cognitive aging and task switching? The combination of cognitive and developmental research and cognitive neuroscience seems to be useful (1) for showing that different task-switching components are indeed subserved by different areas of the brain; and (2) for collecting converging evidence for age-differential changes in executive processes with different methods and electrophysiological and behavioral data.

The specific task-switching component has often been attributed to the prefrontal cortex (Rogers et al., 1998; Shallice; 1994). To date, only a few fMRI studies looked at brain activities during task switching. For instance, Dove et al. (2000) used an event-related fMRI technique and found that the prefrontal cortex is recruited for task switching but no specific region is involved in the execution of a task switch. DiGirolamo et al. (2000) recently observed greater areas of activation in the lateral and medial frontal cortex during switching than repeating tasks for younger and older adults. Older adults recruited frontal lobe areas during switching and repeating trials, whereas young adults recruit medial and dorsolateral prefrontal areas only for switch trials. The findings suggest that older adults also recruit subsystems within the brain that may be needed to monitor conflicts.

To sum up and speculate on the basis of the recent findings in cognitive aging and neuroscience research, we conclude that age-based impairments in task-switching situations are strongly modulated by the level of task uncertainty which is generally higher in competition situations, such as switching between multiple potentially relevant task sets. Task cues reduce task uncertainty and cause age-related differences in the maintenance and selection of task sets decrease or disappear. In contrast, without task cues young and old adults seem to rely on brain subsystems that subserve those processes. Recent neuropsychological evidence suggests that the dorsolateral prefrontal cortex is especially busy with maintaining task representations and supporting processing of task-relevant information, that is, with biasing processing for efficient goal-directed behavior (Banich et al., 2000; Miller \& Cohen, 2001). We also know that the dorsolateral prefrontal cortex undergoes substantial age-related deterioration. In addition, fMRI research supports a strong activation within the prefrontal cortext during switching (e.g., Dove et al., 2000).

The picture is less clear for the specific switching component. The data of the present study also suggests that age-related differences were increased when the number of task sets was increased from two to four. In the present experiment, attributes of all four tasks were mapped onto the same two response keys; thus, cross talk or interference was high at the level of response sets. Recent fMRI studies looking at brain activity when participants switch between two task sets failed to find brain acitivity that was specifically associated with the execution of a task switch. However, a variety of new studies using fMRI techniques and a modified version of the Stroop paradigm claimed that the anterior cingulate cortex may be recruited for monitoring of response conflicts and for detection of errors (Carter et al., 1998). Future research will be necessary to explore which specific role the ACC plays for efficient action regulation and for explaining age changes therein. 


\section{APPENDIX 1}

Means and SDs of Untransformed RTs for Number of Sets,

Age Group, and Trial Type

\begin{tabular}{|c|c|c|c|c|c|c|}
\hline \multirow[b]{2}{*}{ Age group } & \multicolumn{2}{|c|}{ Set Size 1} & \multicolumn{2}{|c|}{ Set Size 2} & \multicolumn{2}{|c|}{ Set Size 4} \\
\hline & $M$ & $S D$ & $M$ & $S D$ & $M$ & $S D$ \\
\hline \multicolumn{7}{|c|}{ Overall } \\
\hline Young & 802 & 163 & 1006 & 246 & 1001 & 251 \\
\hline Old & 993 & 194 & 1341 & 395 & 1421 & 411 \\
\hline \multicolumn{7}{|c|}{ Nonswitch trials } \\
\hline Young & - & - & 924 & 229 & 894 & 210 \\
\hline Old & - & - & 1175 & 359 & 1169 & 329 \\
\hline \multicolumn{7}{|c|}{ Switch trials } \\
\hline Young & - & - & 1075 & 266 & 1092 & 295 \\
\hline Old & - & - & 1485 & 450 & 1637 & 505 \\
\hline
\end{tabular}

APPENDIX 2

Means and SDs of Untransformed RTs for Number of Sets Per Task

\begin{tabular}{|c|c|c|c|c|c|c|}
\hline \multirow[b]{2}{*}{ Age group } & \multicolumn{2}{|c|}{ Set Size 1} & \multicolumn{2}{|c|}{ Set Size 2} & \multicolumn{2}{|c|}{ Set Size 4} \\
\hline & $M$ & $S D$ & $M$ & $S D$ & $M$ & $S D$ \\
\hline \multicolumn{7}{|c|}{ Category } \\
\hline Young & 679 & 132 & 819 & 204 & 800 & 177 \\
\hline Old & 772 & 146 & 1013 & 334 & 1086 & 342 \\
\hline \multicolumn{7}{|c|}{ Syllable } \\
\hline Young & 773 & 213 & 955 & 289 & 986 & 321 \\
\hline Old & 838 & 236 & 1252 & 480 & 1391 & 498 \\
\hline \multicolumn{7}{|c|}{ Letter H } \\
\hline Young & 686 & 163 & 922 & 253 & 897 & 261 \\
\hline Old & 862 & 176 & 1261 & 370 & 1260 & 404 \\
\hline \multicolumn{7}{|c|}{ Number of Letters } \\
\hline Young & 1077 & 227 & 1337 & 331 & 1307 & 322 \\
\hline Old & 1517 & 349 & 1877 & 505 & 1945 & 522 \\
\hline
\end{tabular}

\section{APPENDIX 3}

Comparison between the Computation of General Switch Costs as Orthogonal to Specific Switch Costs or Not Including Switch Trials

\begin{tabular}{|c|c|c|c|c|c|c|}
\hline \multirow[b]{3}{*}{ Source of variation } & \multicolumn{6}{|c|}{ General switch costs } \\
\hline & \multicolumn{3}{|c|}{ Orthogonal contrasts } & \multicolumn{3}{|c|}{ Repeated contrasts } \\
\hline & $F$ & $M S E$ & $p$ & $F$ & $M S E$ & $p$ \\
\hline \multicolumn{7}{|l|}{ Overall (six sessions) } \\
\hline General Costs & 1250.69 & 0.05 & $<.01$ & 511.35 & 0.007 & $<.01$ \\
\hline General Costs by Age 1 & 28.54 & 0.05 & $<.01$ & 33.41 & 0.005 & $<.01$ \\
\hline \multicolumn{7}{|l|}{ Practice (pretest vs posttest) } \\
\hline General Costs by Practice & 235.77 & 0.03 & $<.01$ & 124.76 & 0.009 & $<.01$ \\
\hline General Costs by Practice by Age 1 & 11.54 & 0.03 & $<.01$ & 19.07 & 0.008 & $<.01$ \\
\hline \multicolumn{7}{|l|}{ RSI (200 ms vs 1200 ms) } \\
\hline General Costs by RSI & 429.12 & 0.01 & $<.01$ & 97.68 & 0.003 & $<.01$ \\
\hline General Costs by RSI by Age 1 & & & $n s$ & & & $n s$ \\
\hline
\end{tabular}

Note. RSI $=$ Response-stimulus interval; Age $1=$ performance of young adults was tested against performance of middle-aged and old adults. 


\section{REFERENCES}

Allport, A., Styles, E. A., \& Hsieh, S. (1994). Shifting intentional set: Exploring the dynamic control of tasks. In C. Umiltà \& M. Moscovitch (Eds.), Attention and performance XV (pp. 421-452). Cambridge, MA: Bradford.

Allport, D. A., \& Wylie, G. (1999). Task-switching, stimulus-response bindings, and negative priming. In S. Monsell \& J. Driver (Eds.), Control of cognitive processes: Attention and Performance XVIII. Cambridge, MA: MIT Press.

Banich, M. T., Milham, M. P., Atchley, R. A., Cohen, N. J., Webb, A., Wszalek, T., Kramer, A. F., Liang, Z. P., Barad, V., Gullett, D., Shah, C., \& Brown, C. (2000). Prefrontal regions play a predominant role in imposing an attentional 'set': Evidence from fMRI. Cognitive Brain Research, 10, $1-$ 9.

Brinley, J. F. (1965). Cognitive sets, speed and accuracy of performance in the elderly. In A. T. Welford \& J. E. Birren (Eds.), Behavior, aging, and the nervous system (pp. 114-149). Springfield, IL: Charles C. Thomas.

Carter, C. S., Braver, T. S., Barch, D. M., Botvinick, M. M., Noll, D., \& Cohen, J. D. (1998). Anterior cingulate cortex, error detection, and the online monitoring of performance. Science, 280, 747749 .

Cohen, J. D., Dunbar, K., \& McClelland, J. L. (1990). On the control of automatic processes: A parallel distributed processing account of the Stroop effect. Psychological Review, 97, 332-361.

Craik, F. I. M. (1977). Age differences in human memory. In J. E. Birren \& K. W. Schaie (Eds.), Handbook of the psychology of aging (pp. 384-420). New York: Von Nostrand Reinhold.

De Jong, R., Berendson, E., \& Cools, R. (1999). Goal neglect and inhibitory limitations: Dissociable causes of interference effects in conflict situations. Acta Psychologica, 101, 379-394.

Dempster, F. N. (1992). The rise and fall of the inhibitory mechanism: Toward a unified theory of cognitive development and aging. Developmental Review, 12, 45-75.

DiGirolamo, G. J., Kramer, A. F., Barad, V., Cepeda, N., Weissman, D. H., Milham, M., Wszalek, T. M., Cohen, N. J., Banich, M., Webb, A., \& Belopolsky, A. (April, 2000). General and task-specific frontal lobe recruitment in older adults during executive processes: An fMRI investigation of taskswitching. Presented at the 8th Cognitive Aging Conference, Atlanta, GA.

Dove, A., Pollmann, S., Schubert, T., Wiggins, C. J., \& von Cramon, D. Y. (2000). Prefrontal cortex activation in task switching: An event-related fMRI study. Cognitive Brain Research, 9, 103-109.

Duncan, J. (1995). Attention, intelligence, and the frontal lobes. In M. S. Gazzaniga (Ed.), The cognitive neurosciences (pp. 721-733). Cambridge, MA: MIT Press.

Fabiani, M. \& Wee, E. (2001). Age-related changes in working memory and frontal lobe function: A review. In C. Nelson \& M. Luciana (Eds.). Handbook of developmental cognitive neuroscience. Cambridge, MA: MIT Press.

Frensch, P. A., Lindenberger, U., \& Kray, J. (1999). Imposing structure on an unstructured environment: Ontogenetic changes in the ability to form rules of behavior under conditions of low environmental predictability. In A. Friederici \& R. Menzel (Eds.), Learning: Rule extraction and representation (pp. 139-162). Berlin, Germany: De Gruyter.

Hahn, S., \& Kramer, A. F. (1995). Attentional flexibility and aging: You don't need to be 20 years of age to split the beam. Psychology and Aging, 10, 597-609.

Hartley, A. A. (1992). Attention. In F. I. M. Craik \& T. A. Salthouse (Eds.), The handbook of aging and cognition (1st ed., pp. 3-49). Hillsdale, NJ: Erlbaum.

Hartley, A. A., Kieley, J. M., \& Slabach, E. H. (1990). Age differences and similarities in the effects of cues and prompts. Journal of Experimental Psychology: Human Perception and Performance, 16, 523-537.

Jersild, A. T. (1927). Mental set and shift. Archives of Psychology, No. 89.

Jonides, J., \& Smith, E. F. (1997). The architecture of working memory. In E. D. Rugg, Cognitive neuroscience: Studies in cognition. Cambridge, MA: MIT Press.

Keele, S. W., \& Rafal, B. (2000). Deficits of attentional sets in frontal patients. In S. Monsell \& J. Driver (Eds.), Control of cognitive processes: Attention and performance XVIII. Cambridge, MA: MIT Press.

Kliegl, R., Mayr, U., \& Krampe, R. T. (1994). Time-accuracy functions for determining process and person differences: An application to cognitive aging. Cognitive Psychology, 26, 134-164. 
Kramer, A. F., Hahn, S., \& Gopher, D. (1999). Task coordination and aging: Explorations of executive processing in the task switching paradigm. Acta Psychologica, 101, 339-378.

Kramer, A. F., Larish, J. F., \& Strayer, D. L. (1995). Training of attentional control in dual task settings: A comparison of young and old adults. Journal of Experimental Psychology: Applied, 1, 50-76.

Kray, J., \& Lindenberger, U. (2000). Adult age differences in task switching. Psychology and Aging, 15, 126-147.

Li, K. Z. H., Lindenberger, U., Rünger, D., \& Frensch, P. A. (2000). The role of inhibition in the regulation of sequential action. Psychological Science, 11, 343-347.

Lindenberger, U., Mayr, U., \& Kliegl, R. (1993). Speed and intelligence in old age. Psychology and Aging, 8, 207-220.

Los, S. A. (1996). On the origin of mixing costs: Exporing information processing in pure and mixed blocks of trials. Acta Psychologica, 94, 145-188.

Los, S. A. (1999). Identifying stimuli of different perceptual categories in mixed blocks of trials: Evidence for cost in switching between computational processes. Journal of Experimental Psychology: $\mathrm{Hu}$ man Perception and Performance, 25, 2-23.

MacLeod, C. M. (1991). Half a century of research on the Stroop effect: An integrative review. Psychological Bulletin, 109, 163-203.

Mayr, U., \& Keele, S. (2000). Changing internal constraints on action: The role of backward inhibition. Journal of Experimental Psychology: Learning, Memory, and Cognition, 19, 1297-1320.

Mayr, U. (2001). Age differences in the selection of mental sets: The role of inhibition, stimulus ambiguity, and response-set overlap. Psychology and Aging, 16, 96-109.

Mayr, U., \& Kliegl, R. (1993). Sequential and coordinative complexity: Age-based control limitations in figural transformations. Journal of Experimental Psychology: Learning, Memory, and Cognition, 19, $1297-1320$.

Mayr, U., \& Kliegl, R. (2000). Complex semantic processing in old age: Does it stay or does it go? Psychology and Aging, 15, 29-43.

McDowd, J. M., \& Shaw, R. S. (2000). Attention and aging: A functional perspective. In F. I. M. Craik \& T. A. Salthouse (Eds.), Handbook of aging and cognition (2nd ed., pp. 221-292). Mahwah, NJ: Erlbaum.

Mecklinger, A., von Cramon, D. Y., Springer, A., \& Matthes-von-Cramon, G. (1999). Executive control functions in task switching: Evidence from brain injured patients. Journal of Clinical and Experimental Neuropsychology, 21, 606-619.

Meiran, N. (1996). Reconfiguration of processing mode prior to task performance. Journal of Experimental Psychology: Learning, Memory, and Cognition, 22, 1423-1442.

Meiran, N. (2000). Reconfiguration of stimulus task-sets and response task-sets during task-switching. In S. Monsell \& J. Driver (Eds.), Control of cognitive processes: Attention and performance XVIII. Cambridge, MA: MIT Press.

Miller, E. K., \& Cohen, J. D. (2001). An integrative theory of prefrontal cortex function. Annual Review, 24, 167-202.

Monsell, S. (1996). Control of mental processes. In V. Bruce (Ed.), Unsolved mysteries of the mind: Tutorial essays in cognition (pp. 93-148). Hove, UK: Erlbaum Taylor \& Francis.

Moscovitch, M., \& Winocur, G. (1992). The neuropsychology of memory and aging. In F. I. M. Craik \& T. A. Salthouse (Eds.), Handbook of aging and cognition (1st ed., pp. 315-372). Hillsdale, NJ: Erlbaum.

Norman, D. A., \& Shallice, T. (1986). Attention in action: Willed and automatic control of behavior. In R. J. Davidson, G. E. Schwartz, \& D. Shapiro (Eds.), Consciousness and self-regulation (Vol. 4, pp. 1-18). New York: Plenum Press.

Ratcliff, R. (1993). Methods for dealing with reaction time outliers. Psychological Bulletin, 114, 510532.

Raven, J. C., Court, J. H., \& Raven, J. (1987). A manual for Raven's Progressive Matrices and Vocabulary Tests. London: H. K. Lewis.

Raz, N. (2000). Aging of the brain and its impact on cognitive performance: Integration of structural and functional findings. In F. I. M. Craik \& T. A. Salthouse (Eds.), Handbook of aging and cognition (2nd ed., pp. 1-90). Mahwah, NJ: Erlbaum.

Ridderinkhof, K. R. (2000). The operation of adaptive control processes in task shifting: Rapid adjustment of task set in young and older adults.

Ridderinkhof, K. R., Span, M. M., \& van der Molen, M. W. (2002). Perseverative behavior and adaptive 
control in older adults: Performance monitoring, rule induction, and set shifting. Brain and Cognition, 49, 382-401.

Rogers, R. D., \& Monsell, S. (1995). Costs of a predictable switch between simple cognitive tasks. Journal of Experimental Psychology: General, 124, 207-231.

Rogers, R. D., Sahakian, B. J., Hodges, J. R., Polkey, C. E., Kennard, P. C., \& Robbins, T. W. (1998). Dissociating executive mechanisms of task control following frontal lobe damage and Parkinson's disease. Brain, 121, 815-842.

Phillips, L. H., \& Della Sala, S. (1998). Aging, intelligence, and anatomincal segregation in the frontal lobes. Learning and Individual Differences, 10, 217-243.

Prull, M. W., Gabrieli, J. D. E., \& Bunge, S. A. (2000). Age-related changes in memory: A cognitive neuroscience perspective. In F. I. M. Craik \& T. A. Salthouse (Eds.), Handbook of aging and cognition (pp. 91-154). Mahwah, NJ: Erlbaum.

Salthouse, T. A. (1991). Theoretical perspectives on cognitive aging. Hillsdale, NJ: Erlbaum.

Salthouse, T. A. (1996). The processing-speed theory of adult age differences in cognition. Psychological Review, 103, 403-428.

Salthouse, T. A., Fristoe, N. M., Lineweaver, T. T., \& Coon, V. E. (1995). Aging of attention: Does the ability to divide decline? Memory \& Cognition, 23, 59-71.

Salthouse, T. A., Fristoe, N. M., McGuthry, K. E., \& Hambrick, D. Z. (1998). Relation of task switching to speed, age, and fluid intelligence. Psychology and Aging, 13, 445-461.

Shallice, T. (1994). Multiple levels of control processes. In C. Umiltà \& M. Moscovitch (Eds.), Attention and performance (pp. 395-417). Cambridge, MA: Bradford.

Stayer, D. L., \& Kramer, A. F. (1994a). Strategies and automaticity. I. Basic findings and conceptual framework. Journal of Experimental Psychology: Learning, Memory, and Cognition, 20, 318-341.

Stayer, D. L., \& Kramer, A. F. (1994b) . Strategies and automaticity. II. Dynamic aspects of strategy adjustment. Journal of Experimental Psychology: Learning, Memory, and Cognition, 20, 342-365.

Stuss, D. T., Eskes, G. A., \& Foster, J. K. (1994). Experimental neuropsychological studies of frontal lobe functions. In F. Boller, H. Spinnler, \& J. A. Hendler (Eds.), Handbook of neuropsychology (Vol. 9, pp. 149-185). Amsterdam: Elsevier.

Tipper, S. P., Weaver, B., Cameron, S., Brehaut, J. C., \& Bastedo, J. (1991). Inhibitory mechanisms of attention in identification and localization tasks: Time course and disruption. Journal of Experimental Psychology: Learning, Memory, and Cognition, 17, 681-692.

Tranel, D., Anderson, S. W., \& Benton, A. (1994). Development of the concept of “executive function" and its relationship to the frontal lobes. In F. Boller, H. Spinnler, \& J. A. Hendler (Eds.), Handbook of neuropsychology (Vol. 9, pp. 125-148). Amsterdam: Elsevier.

Verhaeghen, P., Kliegl, R., \& Mayr, U. (1997). Sequential and coordinative complexity in time-accuracy functions for mental arithmetic. Psychology and Aging, 12, 555-564.

Verhaeghen, P., \& Salthouse, T. A. (1997). Meta-analyses of age-cognition relations in adulthood: Estimates of linear and nonlinear age effects and structural models. Psychological Bulletin, 122, 231249.

Van Asselen, M., \& Ridderinkhof, K. R. (2000). Shift costs of predictable and unexpected set shifting in young and older adults. Psychologica Belgica, 40, 259-273.

van der Molen, M. W., \& Ridderinkhof, K. R. (1998). The growing and aging brain: Life-span changes in brain and cognitive functioning. In A. Dementriou, W. Doise, \& C. F. M. van Lieshout (Eds.), Life-span development psychology: A European perspective (pp. 35-100). New York: Wiley.

Wechsler, W. (1982). Handanweisung zum Hamburg-Wechsler-Intelligenztest für Erwachsene (HAWIE). [Manual for the Hamburg-Wechsler Intelligence Test for Adults]. Bern, Switzerland: Huber.

West, R. L. (1996). An application of prefrontal cortex function theory to cognitive aging. Psychological Bulletin, 120, 272-292.

Zacks, R. T., Hasher, L., \& Li, K. Z. H. (2000). Human memory. In F. I. M. Craik \& T. A. Salthouse (eds.), Handbook of aging and cognition (2nd ed., pp. 293-359). Mahwah, NJ: Erlbaum. 